This is a PDF file of an unedited manuscript that has been accepted for publication in Computers and Operations Research.

The manuscript will undergo copyediting, typesetting, and review of the resulting proof before it is published in its final form. Please note that during the production process errors may be discovered which could affect the content, and all legal disclaimers that apply to the journal pertain.

\title{
Multiobjective programming for sizing and locating Biogas Plants: a model and an application in a region of Portugal
}

Sandra Silva (a b), Luís Alçada-Almeida (b c), Luís C. Dias (b c)

(a) Polytechnic Institute of Viana do Castelo, Praça General Barbosa 4900-347, Viana do Castelo, Portugal

Tel.: +351258 809 610; Fax: +351258 829 065; E-mail:sandrasilva@esa.ipvc.pt

(b) Institute for Systems Engineering and Computers, Rua Antero de Quental, №199, 3000 - 033 Coimbra, Portugal.

Tel.: +351239 851040/9; Fax: +351239824692

(c) CeBER and Faculty of Economics, University Coimbra, Av. Dias da Silva, 165, 3004-512 Coimbra, Portugal

Tel: +351239790 500; Fax: +351239790514

E-mail: sandrasilva@esa.ipvc.pt

\section{Abstract:}

The location of undesirable facilities involves economic, environmental and social impacts. The costs associated and the rejection of facilities by nearby population are crucial concerns. This paper introduces a Multiobjective Mixed-Integer Linear Programming (MMILP) approach to identify locations and capacities of biogas plants to treat animal waste from dairy farms, and assign each farm to a subset of the opened biogas plants. Three objectives were considered in the mathematical model: minimizing initial investment, operation and maintenance costs; minimizing transportation cost; and minimizing social rejection. The proposed model was applied to the Entre-Douro-e-Minho Region in Portugal. The approach provided as output a set of Pareto optimal solutions, represented by maps using a Geographic Information System, each one achieving a unique combination of economic and social performance.

Keywords: Location; Multiple objective programming; Bioenergy; Geographical Information Systems. 


\section{Introduction}

Animal waste has the potential to become an important renewable energy resource, since methane gas is produced naturally by manure. An Anaerobic Digester (AD) energy system promotes methane production, captures and converts it into electricity and heat, and also yields a fertilizer. There is growing interest in installing AD Biogas Plants in order to use animal waste as a biomass resource. This yields economic value and environmental benefit by improving the quality of the fertilizer, reducing odours and pathogens and producing a renewable energy (Taleghani and Kia, 2005 and Ma et al., 2005). On the other hand, given the nature of these facilities, it is nearly always the case that opposition is encountered where they are sited, which is often dubbed as the "not in my backyard" (NIMBY) phenomenon. NIMBY refers to the well-known fact that residents tend to oppose the location of undesirable facilities near their homes, citing health and safety risks, depreciation of property value, degradation of the "quality of life" of nearby population centres, and environmental damage.

The complexity of finding a location for undesirable facilities lies mostly in the existence of at least partially conflicting objectives concerning total cost, potential risk, risk equity, social rejection, security, and so on. During the decision-making process, many conflicting objectives of different stakeholders need to be considered in the search for good compromise solutions (Samanlioglu, 2013). Tools based on multiobjective mathematical programming are well suited to tackle this problem, as they allow a rigorous and systematic screening of a large number of alternatives. Erkut and Neuman (1989) further emphasize the need for multi-objective approaches to the siting of undesirable facilities when they state that "the multiple constituency, multiobjective nature of the problem severely limits the usefulness of single objective models". The inclusion of multiple, conflicting objectives, enhances the analysis and leads to model formulations where the concept of an optimal solution is replaced with that of an efficient solution, also referred to as non-dominated, non-inferior, or Pareto optimal solution (Cohon, 1978). The final goal is to find solutions in the set of Pareto optimal alternatives, that is, solutions with the property of being impossible to improve one of the objectives without necessarily worsening at least another objective.

In the last three decades, researchers have been interested in the multiobjective location problem (Farahani et al., 2010). Examples include the location of undesirable facilities such as hazardous material (Wyman and Kuby, 1993 and 1995), sanitary landfills (Melachrinoudis et al., 1995), municipal solid waste management facilities (Erkut et al., 2008), incineration facilities (Alçada-Almeida et al., 2009), semi-desirable urban facilities (CoutinhoRodrigues et al., 2012) and semi obnoxious or obnoxious facilities (Fonseca and Captivo, 1996). Other researchers developed a model for the problem of not only locating undesirable facilities, but also routing the undesirable materials (Giannikos, 1998; Cappanera et al., 2004, Rakas et al., 2004, Caballero et al., 2007; Alumur and Kara, 2007; Samanlioglu, 2013).

Siting, particularly bioenergy plants, is a challenging task. There are various studies related to biogas plants concerning different aspects that can influence location decisions, such as the current situation and potential in production and utilization of biogas (HolmNielsen et al., 2009; Tricase and Lombardi, 2009; Gómez et al, 2010; Salomon and Lora, 2009 and Ulusoy et al, 2009), economic and environmental sustainability of biogas (Maeng et al, 1999; Jingura and Matengaifa, 2009; Murphy et al, 2004; Taleghani and Kia, 2005, Neves et al, 2009; Madlener et al, 2009), or supply chain management at the strategic and tactical decision level in bioenergy industry (Melo et al, 2009; Meyer et al., 2015).

There are also studies on the role of Geographical Information Systems (GIS) in the mapping and evaluation of locations for biogas plants (Church, 2002; Dagnall et al., 2000; Batzias et al., 2005; Voivontas et al., 2001; Madlener and Schmid, 2009; Panichelli and Gnansounou, 2008; Sultana and Kumar, 2012). GIS can assist the location modelling and analysis process by helping to gather, structure, filter, and analyse input data and by 
presenting model outputs in a way that helps decision makers understand spatial consequences (Alçada-Almeida et al., 2009).

In this research we address the problem of locating biogas plants that use manure from dairy farms, simultaneously defining the size of the plant at each location and the amount of manure from each dairy farm to be processed at each plant. We formulated a Multiobjective Mixed-Integer Linear Program (MMILP) considering three objectives: two economic objectives and a social objective. Several factors are considered in the model: location of the basic resource, physical and practical constraints on our ability to harness it, environmental and regulatory restrictions, and economic and social considerations. We used this model to solve a problem with real data from Entre-Douro-e-Minho Region in Portugal, assisted by the use of a GIS to collect and process georeferenced data.

\section{Multiobjective model for location of Biogas Plants}

The objectives considered take into account economic aspects as well a social concern. The economic objectives are two: the minimization of implementation, operation and maintenance costs, and the minimization of transport costs. These two types of cost are in conflict, since implementation costs favour fewer and larger facilities (economies of scale), whereas transport costs favour more and hence smaller facilities. For this reason, and also because these costs may be incurred by different entities, we considered each of them as a distinct objective. The social objective considered is the minimization of social rejection, since biogas plants cause opposition from nearby population. The economic and social objectives are potentially conflicting. Social rejection is often in conflict with transport costs: the greater the distance between the candidate sites and the places where people live, the lower the social rejection but this increases the cost of transport. On the other hand, social rejection and maintenance and operation cost are also likely to be in conflict: smaller plants lead to lower rejection from nearby populations but this implies an increase in costs. Thus, we present a triobjective mixed-integer linear programming formulation.

In our model, we assumed that we have a discrete problem, in which several candidate sites for the facilities have already been selected using for instance the approach described by Silva et al. (2014). Identifying an initial set of potential locations corresponds to a common practice in real-world applications because environmental and social concerns impose constraints on the location of undesirable facilities. We have selected a set of adequate sites for the location of biogas plants by performing a land-use suitability analysis, through a combination of GIS and a multicriteria sorting method (Silva et al., 2014). A variety of logistic constraints, as well as economic, environmental and social factors were integrated in the suitability analysis to exclude areas which contain or are too close to water lines, protected areas, urban areas, or are too far from the electricity grid, for example.

There are different types of biogas plants, which can be categorized according to the type of digested substrate, used technology, or size (Holm-Nielsen et al., 2009). Al Seadi et al. (2008) classified biogas plants based on their relative size, function and location in three groups: family scale biogas plants (very small scale); farm scale biogas plants (small or medium to large scale) and centralised/joint co-digestion plants (medium to large scale). Dagnall et al. (2000) refers that two options are being seriously considered by industry in Europe: centralised anaerobic digestion (AD) and direct combustion. In our study, we considered that biogas plants are centralised. This means that animal manure and slurries, collected from several farms, are digested in a biogas plant centrally located in the manure collection area. The central location of the biogas plant aims to reduce costs, time and manpower (Al Seadi et al., 2008).

Biogas plants have some characteristics related to operation, type of substrate (in this case study, only manure from dairy farms), technical structure, dimension, etc., that needed to 
be modelled. We assume that the total manure produced in a dairy farm was treated, and could be associated with more than one biogas plant (i.e., if the volume of each fraction justifies it, part of the manure from a farm could go to a plant, and another part could go to other plants).

We considered that each plant could have one of three sizes, according to the amount of manure processed and amount of electricity produced. The three types of biogas plant are named Mini, Base and Large. Based on the literature, we defined the minimum and maximum amount of manure for each type of plant to ensure that it would be economically and technically feasible. According to the type of plant to be installed, it is also necessary that the potential site has a required minimum area. Finally, we require that the distance between dairy farms and plants cannot exceed a fixed maximum distance (a parameter of the model) for the manure to preserve its properties and also to reduce the risks associated with transportation.

In our model, we assumed that the three types of plant (Mini, Base and Large) have different values for the initial investment and maintenance costs. The initial investment and lifetime maintenance costs of the biogas plant are subject to economies of scale (Nielsen et al., 2002; Baldwin et al., 2009), so it may be economically preferable to build larger-scale plants.

The transportation cost of manure from dairy farms to biogas plants is a key aspect to consider in the location of these facilities. The transport costs considered in this study are based on the amount of manure transported, the distance transported (round trip), and the unit transport cost. To avoid impractical solutions, we considered a minimum amount of manure to justify the transportation from dairy farm to plant, as well as an upper limit to the number of plants associated to each dairy farm.

Finally, we sought to minimize the opposition of the population near a biogas plant (social rejection). We can find different definitions of social rejection in the literature. Erkut and Neuman (1992) based the opposition on the notion of disutility, which is assumed to depend on the distance between a facility and the surrounding population, and the scale of the facility. Callabero et al. (2007) defined the social rejection from towns near an incineration plant as an increasing function of town size and a decreasing function of distance from the plant to the nearby town. In the present work, the collective disutility was defined as a function of the population located in a radius of $\theta \mathrm{km}$ from potential sites and the type of biogas plant.

\subsection{Model formulation}

Having described the main assumptions and modelling options, we now present in detail the tri-objective MILP model developed for this application:

Indices:

$i$ - index referring to the dairy farms $(i=1,2, \ldots, m)$;

$j$ - index referring to the potential sites for the location of biogas plants $(j=1,2, \ldots, n)$;

$k$ - index for biogas plant types $(k=1, \ldots, l)$;

$h$ - index referring to the parishes in the region $(h=1, \ldots, p)$.

\section{Parameters:}

$m_{i}$ amount of manure ( $\mathrm{m}^{3} /$ day) produced by dairy farm $i$;

$m_{i}^{\min }$ minimum amount of manure $\left(\mathrm{m}^{3} /\right.$ day) that justifies the transportation from dairy farm $i$ to any biogas plant; 
$m^{\text {pmin }}$ minimum percentage of manure produced by any dairy farm that justifies the transportation to any biogas plant;

$m^{\max }$ maximum amount of manure $\left(\mathrm{m}^{3} /\right.$ day) possible to transport between any dairy farm and any biogas plant;

$t^{\text {min }}$ minimum amount of manure $\left(\mathrm{m}^{3} /\right.$ day) that can be transported from any single dairy farm to any biogas plant;

$c_{k}^{\min }$ minimum amount of manure $\left(\mathrm{m}^{3} /\right.$ day) required to install a biogas plant of type $k$;

$c_{k}^{\max }$ maximum amount of manure $\left(\mathrm{m}^{3} /\right.$ day $)$ that can be processed by a biogas plant of type $k$;

$b^{\max }$ maximum number of biogas plants serving a dairy farm;

$a_{j}$ area of site $j$;

$a_{k}^{\min }$ minimum area (ha) required for the installation of a biogas plant of type $k$;

$d_{i j}$ road distance $(\mathrm{km})$ between dairy farm $i$ and site $j$;

$d$ maximum allowable distance $(\mathrm{km})$ from a dairy farm to a biogas plant;

$v$ lifetime of biogas plant (years);

$t$ cost of transportation $(€)$ of $1 \mathrm{~m}^{3}$ of manure per $\mathrm{km}$;

$f_{k}$ initial investment cost (€) of a biogas plant of type $k$;

$g_{k}$ annual operation and maintenance costs ( $€$ /year) for a biogas plant of type $k$;

$\theta$ radius $(\mathrm{km})$ from any potential site, of concern to the population due to its proximity to the biogas plant (fixed distance);

$r_{h j k}$ social rejection at parish $h$, if a biogas plant of type $k$ is located at site $j$;

$p_{h}$ population in parish $h$;

$a_{h}$ area (ha) of parish $h$;

$a_{h j}^{\theta}$ area (ha) of the parish $h$ that is contained in the buffer of $\theta \mathrm{km}$ from site $j$;

$p_{j}^{\theta}$ number of persons who are at a distance of $\theta \mathrm{km}$ from site $j$;

$s_{k}$ social penalty of population according to the type of biogas plant $k$.

\section{Variables:}

$x_{i j}$ binary variable: $x_{i j}=1$ if a transportation link between dairy farm $i$ and site $j$ is established; $x_{i j}=0$ otherwise. This variable is considered null (parameter) for pairs $(i, j)$ such that $d_{i j}>d$ (i.e., the model imposes a maximum distance from biogas plants to assigned dairy farms);

$q_{i j}$ real variable: amount of manure to transport daily $\left(\mathrm{m}^{3}\right)$ from dairy farm $i$ to site $j$. This variable is considered null (parameter) in the same circumstance as $x_{i j}$.

$y_{j k}$ binary variable: $y_{j k}=1$ if a biogas plant of type $k$ is located at site $j ; y_{j k}=0$ otherwise. This variable is considered null for pairs $(j, k)$ such that $a_{j}<a_{k}^{\min }$ (i.e., the potential location of a plant of type $k$ on site $j$ is not allowed if the area of site $j$ is less than that required by a plant of that type).

The following objective functions and constraints are formulated:

$$
\text { Min } \quad Z_{1}=\sum_{j=1}^{n} \sum_{k=1}^{l}\left(f_{k}+v g_{k}\right) y_{j k}
$$




$$
\begin{gathered}
\text { Min } Z_{2}=\sum_{i=1}^{m} \sum_{j=1}^{n} 2 t d_{i j} q_{i j} \\
\operatorname{Min} Z_{3}=\sum_{h=1}^{p} \sum_{j=1}^{n} \sum_{k=1}^{l} r_{h j k} y_{j k}=\sum_{j=1}^{n} \sum_{k=1}^{l} p_{j}^{\theta} s_{k} y_{j k}
\end{gathered}
$$

\section{Subject to:}

$$
\begin{aligned}
& \sum_{j=1}^{n} q_{i j}=m_{i}, \quad \forall i \\
& \sum_{k=1}^{l} y_{j k} \leq 1, \quad \forall j \\
& \sum_{k=1}^{l} c_{k}^{\text {min }} y_{j k} \leq \sum_{i=1}^{m} q_{i j} \leq \sum_{k=1}^{l} c_{k}^{\max } y_{j k}, \quad \forall j \\
& m_{i}^{\min } x_{i j} \leq q_{i j} \leq m^{\max } x_{i j}, \quad \forall i, j \\
& q_{i j} \geq m^{\text {min }} m_{i} x_{i j}, \quad \forall i, j \\
& \sum_{j=1}^{n} x_{i j} \leq b^{\text {max }}, \quad \forall i \\
& x_{i j}, y_{j k} \in\{0,1\}, \quad \forall i, j, k
\end{aligned}
$$

The first objective (1) was to minimize investment and lifetime operation and maintenance costs (reported in euros). The second objective (2) was to minimize transport costs (also reported in euros). The model does not go into detail concerning the type of truck, considering instead a fixed cost per $\mathrm{m}^{3}$, per $\mathrm{km}$ (this could be defined in a contract with a transportation company). The third objective (3) took into account the social rejection from the population within a buffer of $\theta \mathrm{km}$ from each potential site $j$, measured in number of equivalent persons. The population included in the buffer of $\theta \mathrm{km}$ for each site $j\left(p_{j}^{\theta}\right)$ was determined by the ratio of the area of intersection with the parish in the buffer $\left(a_{h j}^{\theta}\right)$ and the total area of the parish $\left(a_{h}\right)$, which was multiplied by the total population in the respective parishes $\left(p_{h}\right)$, as follows:

$$
p_{j}^{\theta}=\sum_{h=1}^{p} p_{h} \times \frac{a_{h j}^{\theta}}{a_{h}}
$$

In addition, a penalizing factor $\left(s_{k}\right)$ was introduced, which is related to the type of plant implemented in accordance with the area occupied by it. The impact of a particular type of plant among populations is considered to be proportional to the area that the infrastructure occupies: $s_{k}=a_{k}^{\min }, \forall k=\{1,2,3\}$. The measurement of objective $Z_{3}$ is admittedly a simplification based on this assumption and the additional assumption that the population of a parish is uniformly distributed in its area. In future applications this MILP formulation can be implemented without changes using a different method to assess the $r_{h j k}$ parameters. 
The constraints presented above ensure that: (4) the daily amount of manure transported from any dairy farm to the associated set of biogas plants is the same as the amount of manure produced in that dairy farm; (5) only one biogas type can be implemented (if any) at each site; (6) the capacity of manure treatment per day lies between the minimum and maximum capacity of manure treatment (in $\mathrm{m}^{3}$ ) of each (opened) biogas plant type; (7) the daily amount of manure transported from any dairy farm to a given associated opened biogas plant must be greater than or equal to a minimum amount that may depend on dairy farm $\left(m_{i}^{\min }\right)$ and cannot exceed a fixed maximum amount $\left(m^{\max }\right)$; in this application we consider $m_{i}^{\min }=\operatorname{Minimum}\left(t^{\min }, m_{i}\right)$, i.e. in cases where the amount produced by the dairy farm, $m_{i}$, is less than the minimum amount to justify transportation ( $t^{\mathrm{min}}$, a fixed value defined by the decision maker for all the farms), then the minimum amount to be transported is decreased to $m_{i} ;(8)$ the daily amount of manure transported from any dairy farm to a given associated biogas plant must be greater than a relative percentage amount of the manure $\left(\mathrm{m}^{\text {pmin }}\right)$ produced by dairy farm; (9) the number of biogas plants associated with each dairy farm is less than or equal to a given maximum $\left(b^{\max }\right)$; $(10)$ the variables that represent allocations of biogas plants and transportation links are binary ( $1=$ chosen, $0=$ not chosen).

\subsection{Application of MILP in EDM Region}

The Entre-Douro-e-Minho (EDM) Region the northwest of Portugal consists of a set of 10 counties (Figure 1 ) with an area of $1,584 \mathrm{~km}^{2}$. These counties have in total 294 parishes $(p=294)$. This region has 1,705 dairy farms $(m=1705)$ with more than 100,000 animals, which produce approximately 1.5 million $\mathrm{m}^{3}$ /year of manure and slurry, i.e. about 4,017 $\mathrm{m}^{3} /$ day. The database of dairy farms considered in this application was obtained from a survey developed during the implementation of the Basin Plan Land Dairy Primary Entre Douro and Minho (POBLPEMD, 2007).

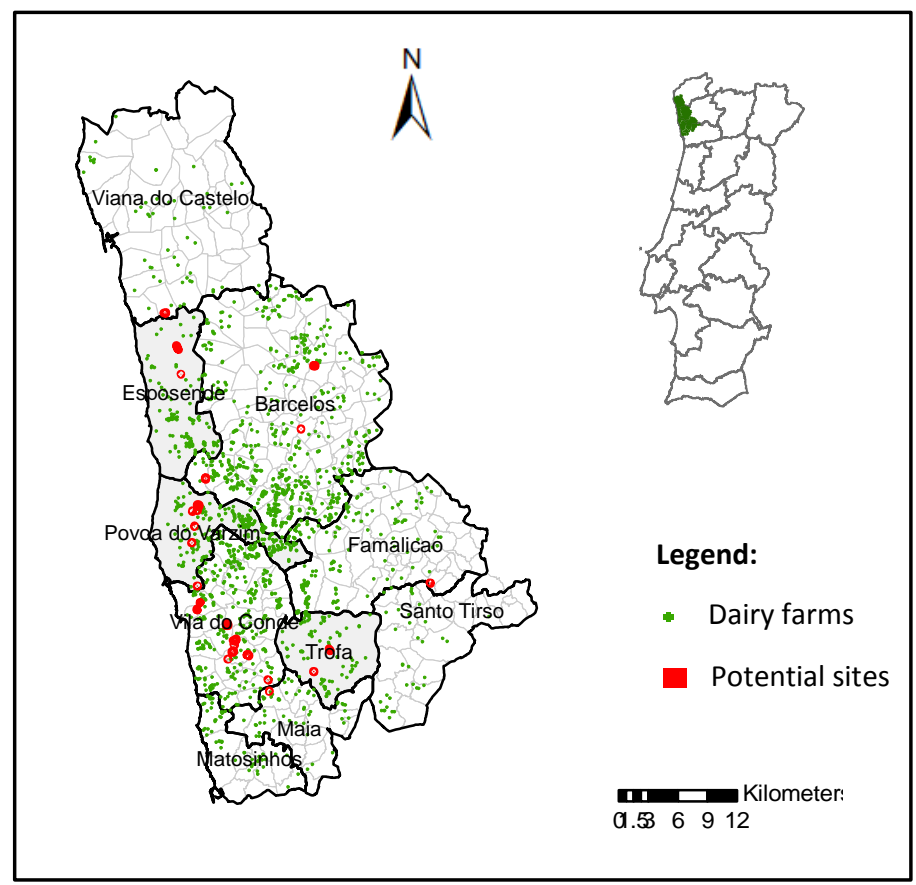

Figure 1: Map of the spatial distribution of dairy farms and potential sites. 
In a previous suitability analysis study, we have identified 41 plots as being the most suitable for locating biogas plants (Silva et al., 2014). By aggregating contiguous plots, we obtained 27 sites $(n=27)$, with areas ranging from 1.038 to 6.674 ha (Figure 1 ), which were considered as potential locations for biogas plants in this study. Biogas Plants with different capacities were defined $(l=3$ ) based on the energy produced (Table 1): Mini, requiring 1 ha and producing up to $200 \mathrm{kWe} /$ day $(\mathrm{k}=1)$; Base, requiring 1.5 ha and producing up to 500 $\mathrm{kWe} /$ day $(\mathrm{k}=2)$; and Large, requiring 2.5 ha and producing up to $1000 \mathrm{kWe} /$ day $(\mathrm{k}=3)$. These minimum required areas for installation should be interpreted as indicative, since the actual area may depends on the technology chosen and other site specific topological characteristics.

The production of biogas assumed in this study was based on several technical, environmental and economic studies (Murphy et al., 2004; Dagnall et al., 2000; Ciborowski, 2001; Caslin, 2009), which indicated the amount of electrical energy in kWh obtained from 1 $\mathrm{m}^{3}$ of biogas effluent and the number of animals needed for the production of $1 \mathrm{~m}^{3}$ of biogas. The capacity of biogas plants is subject to logistical difficulties, mostly associated with the transportation of waste, and waste handling, according to ADENE (2003). To be economically and technically viable to install an $A D$ system it is necessary to have a minimum number of cows: Ma et al. (2005) refers at least 400 milk cows and Ciborowski (2001) refers a range of 500 to 800 cows. In this study we consider the bounds in Table 1 for the different types of plant.

The initial investment includes the anaerobic digestion units: tanks for digesters, tanks for cleaning, separate tanks for product, purification of biogas, gasometers, gas boiler, cogeneration plant and pipework. Based on studies in the United Kingdom and Italy (AEBIOM, 2009), we defined the initial cost associated with the three types of biogas plants (defined similarly to our study) as a function of electrical output. Costs of operation and maintenance refer primarily to staff costs, administrative costs and consumptions. This work, like other studies (Demuynck et al., 1984; ADENE, 2003; Naskeo Environnement, 2009) considered that the annual operation and maintenance costs of a biogas plant represent on average $2 \%$ of the investment cost. Operation and maintenance costs were calculated for a plant with a lifetime of 20 years (i.e., $v=20$ ), based in Stucki et al. (2012).

\begin{tabular}{|c|c|c|c|c|c|c|c|c|}
\hline & \multirow{2}{*}{$\begin{array}{c}\begin{array}{c}\text { Minimum } \\
\text { amount } \\
\text { of manure } \\
\left(\boldsymbol{m}^{3} / \text { day }\right)\end{array} \\
c_{k}^{\text {min }}\end{array}$} & \multirow{2}{*}{$\begin{array}{c}\begin{array}{c}\text { Maximum } \\
\text { amount of } \\
\text { manure } \\
\left(\boldsymbol{m}^{3} / \text { day }\right)\end{array} \\
c_{k}^{\max }\end{array}$} & \multirow{2}{*}{$\begin{array}{c}\begin{array}{c}\text { Cost }(€) \text { to } \\
\text { initial } \\
\text { investment }\end{array} \\
f_{k}\end{array}$} & \multirow{2}{*}{$\begin{array}{c}\begin{array}{c}\text { Operation } \\
\text { and } \\
\text { maintenance } \\
\text { cost (€/year) }\end{array} \\
g_{k}\end{array}$} & \multirow{2}{*}{\begin{tabular}{|c|}
$\begin{array}{c}\text { Minimum } \\
\text { area (ha) } \\
\text { required }\end{array}$ \\
$a_{k}^{\text {min }}$
\end{tabular}} \\
\hline Name & Type & $\begin{array}{l}\text { Electricity } \\
\text { produced } \\
\text { (kWe/day) }\end{array}$ & $\begin{array}{l}\text { Number } \\
\text { of } \\
\text { animals }\end{array}$ & & & & & \\
\hline Mini & $\begin{array}{c}200 \\
\mathrm{kWe}\end{array}$ & $100-200$ & $\begin{array}{l}800- \\
1,600\end{array}$ & 42 & 84 & 980,000 & 19,600 & 1 \\
\hline Base & $\begin{array}{l}500 \\
\mathrm{kWe}\end{array}$ & $200-500$ & $\begin{array}{l}1,600- \\
4,000\end{array}$ & 84 & 210 & $1,900,000$ & 38,000 & 1.5 \\
\hline Large & $\begin{array}{l}1,000 \\
k W e\end{array}$ & $500-1,000$ & \begin{tabular}{|c|}
$4,000-$ \\
8,000
\end{tabular} & 210 & 420 & $3,200,000$ & 64,000 & 2.5 \\
\hline
\end{tabular}

Table 1: Types of Biogas Plants and their characteristics: electricity produced, number of animals, minimum and maximum amount of manure, costs and minimum area.

The transportation cost of waste from dairy farms is a key aspect to consider in the location of biogas plants. We considered the road distance obtained by the Google Distance Matrix API. The information returned is based on the recommended route between origins (dairy farms) and destinations (potential sites), as calculated by the Google Maps API, and 
consists of rows containing distance and duration values for each pair. An automated procedure was developed to obtain this data, since there are 46035 pairs between start and end points and the Distance Matrix API has limits per query.

It was assumed that the transport of manure and slurry would be made on a vacuum tank truck and that the collection of manure on dairy farms would be performed daily, given the need for a continuous supply of feedstock and also to prevent its degradation. The production of manure in the farms studied ranges from about $0.06 \mathrm{~m}^{3} /$ day in smaller farms to approximately $26 \mathrm{~m}^{3} /$ day in larger farms. The cost of transporting manure from farms to biogas plants was determined considering an average unit cost per volume and distance travelled. We considered an average unit cost for the transport of manure of $0.12 € /\left(\mathrm{m}^{3} . \mathrm{km}\right)$ according to Durão (2009), i.e., $t=0.12$.

The maximum distance considered in manure collection varies from author to author and is often associated with the concentration of organic matter. ADENE (2003) advocated distances up to $15 \mathrm{~km}$ between the dairy farms and biogas plants. Durão (2009) admitted a maximum distance of $25 \mathrm{~km}$ for transporting waste, Unal et al. (2011) considered a distance of $40 \mathrm{~km}$ and Dagnall et al. (2000) considered the transport distances to biomass-to-energy facilities lie in the range 10 to $40 \mathrm{~km}$. The maximum distance to transport the manure in this study was considered to be $30 \mathrm{~km}(d=30)$, a value in-between those suggested by different authors, noting that all dairy farms in the area had at least one potential site available within this distance. An analysis to assess the sensitivity of results to this parameter was performed later.

Another concept of distance used is related to social rejection. We considered that a parish is in the vicinity of a biogas plant if it is at a distance less than or equal to a $3 \mathrm{~km}$ radius, i.e., in our study $\theta=3$.

We considered that the maximum amount of waste to be transported from a dairy farm to a biogas plant is the maximum transport capacity of the tanker, $30 \mathrm{~m}^{3}$, i.e., $\mathrm{m}^{\max }=30$. As a minimum value of transport between a dairy farm and a biogas plant we considered $2 \mathrm{~m}^{3}$, i.e., $t^{\min }=2$. This minimum value was defined considering the average amount of waste produced on farms and also for representing a value between $5 \%$ and $10 \%$ of the maximum transport capacity. The minimum percentage of waste to be transported from a given dairy farm was defined as $20 \%$ of its daily production, i.e., $m^{\text {pmin }}=20 \%$. Finally, we considered a maximum of three biogas plants associated with each dairy farm, i.e., $b^{\max }=3$, so that the associated logistics do not become impracticable.

\section{Results}

The MMILP model presented contains 3 objective functions, 93,230 constraints and 59,875 variables (29,962 of which are binary). The results were obtained using CPLEX 12.6.3 as a solver.

The purpose of the analysis was to calculate a few contrasting Pareto optimal (efficient) solutions. To find a subset of efficient solutions we used two approaches: (1) Weighting Method - to construct an aggregate objective function by taking a weighted sum of the objectives and (2) Distance Method - to compute an efficient solution that is as close as possible (according to a given metric) to the aspirations of the decision maker. A particular case of the latter is compromise programming, where the (normalized) distance to the ideal point is minimized (Zeleny, 1973).

In a first step, each objective function was individually minimized, considering very small weights $(\varepsilon)$ on the other two objectives to ensure the identification of an efficient solution (Ehrgott, 2005) and optimal solutions for each objective functions were obtained: Opt1, Opt2 
and $O p t 3$. The objective function values of these three solutions are presented in Table 2, where the individual optimum values are highlighted in bold. The "ideal solution" or utopia point $z^{*}=(46,032 ; 7,604 ; 263,909)$ is given in the row labelled "Ideal". Usually, this solution is not feasible unless a single solution is optimal for all of the objectives, which was not the case in this problem. The nadir point, derived from the worst (i.e., maximum) values observed in $O p t 1, O p t 2$ and $O p t 3$ was identified, $z^{\text {nad }}=(55,832 ; 10,980 ; 542,178)$, represented in the row labelled "Nadir" in Table 2.

In the weighting method (Approach 1) the three objective functions were scaled (normalized) and combined in one objective using weights $\left(\lambda_{1}, \lambda_{2}, \lambda_{3}\right.$, such that $\left.\sum_{i=1}^{3} \lambda_{i}=1\right)$, as follows: $\lambda_{1} \times \frac{Z_{1}}{o p t 1}+\lambda_{2} \times \frac{Z_{2}}{o p t 2}+\lambda_{3} \times \frac{Z_{3}}{o p t 3}$. Here, $\frac{Z_{1}}{o p t 1}$ represents the percent deviation from Opt 1 in the first objective, etc. Normalization is useful since the objective functions have different units/scales. This ensures that the solutions are in compliance with the specification of the underlying preference weights, and avoids giving more relevance to the objectives of greater magnitude.

To determine representative efficient solutions from the Pareto frontier using the Weighting Method, a group of seven weight vectors were generated - Solution 5: Weighted $(0.33 ; 0.33 ; 0.33)$, Solution 6 : Weighted $(0.30 ; 0.40 ; 0.30)$, Solution 7 : Weighted $(0.25 ; 0.50$; $0.25)$, Solution 8: Weighted $(0.20 ; 0.60 ; 0.20)$, Solution 9 : Weighted $(0.15 ; 0.70 ; 0.15)$, Solution 10: Weighted $(0.10 ; 0.80 ; 0.10)$ and Solution 11 : Weighted $(0.05 ; 0.90 ; 0.05)$ in Table 2. For each solution, the relative distances (\%) of each objective value to their respective optimum are given in columns " $\Delta$ Opt1", " $\Delta$ Opt2" and " $\Delta$ Opt3" (Table 2 ).

In the Distance method (Approach 2), the distance of each solution to the "reference point" (considering the objectives' space) was evaluated using two frequently adopted metrics (Bowman, 1976; Steuer, 1986): the Rectilinear or Manhattan metric (L1) and the Chebyshev $(\llcorner\infty)$ metric. We used the ideal solution as reference point to identify two additional nondominated solutions using goal programming, where the "goals" are the ideal solution value for each objective. Solution 4 (Table 2, row "Goal Lo (Norm)") measures the relative (normalized) distances from the goals using the Lo metric. Using the L1 metric led to Solution 5 named "Goal L1 (Norm) $(0.33 ; 0.33 ; 0.33)$ " in Table 2, because minimizing the L1 distance is equivalent to minimizing a weighted sum with equal normalized weights.

Considering the capacity of each biogas plant type, to process all the manure produced in the 1705 dairy farms (about $4017 \mathrm{~m}^{3}$ per day) it is necessary to open, at least, 13 sites (solutions 1, 5 and 6 in Table 2). By minimizing investment, operation and maintenance costs we obtained a solution with 13 biogas plants (Solution 1), favouring opening larger plants of Base and Large types as they are cheaper per unit $\left(\mathrm{m}^{3}\right)$ processed. By minimizing transportation costs, the number of plants increased, reaching its maximum value (26 biogas plants, most of them of type Mini - Solution 2). This causes an increase in investment, operation and maintenance costs. By minimizing social rejection, we obtained 15 biogas plants (Solution 3). This solution favours the implementation of Base and Large biogas plant types to process large quantities of manure in a few locations and therefore avoiding opening plants in other places with more population. This increases significantly transportation costs. As a result, the first and third objectives suggested similar solutions, both favouring configurations with few but larger facilities, in conflict with the second objective which suggested opening a large number of smaller facilities. Solution 4 opens 15 biogas plants and solution 5 opens 13 plants. In other weighted solutions with increasing weight on the second objective function, the number of biogas plants to be installed also increased, as expected. 


\begin{tabular}{|c|c|c|c|c|c|c|c|c|c|c|c|c|c|c|c|}
\hline & \multirow{2}{*}{$\begin{array}{c}\text { Solutions } \\
\text { Designation }\end{array}$} & \multicolumn{3}{|c|}{ Objectives } & \multirow[b]{2}{*}{$\begin{array}{l}\text { Number } \\
\text { Biogas } \\
\text { Plants }\end{array}$} & \multicolumn{3}{|c|}{ Biogas Plant Types } & \multicolumn{3}{|c|}{$\begin{array}{l}\text { Percentual distance to } \\
\text { individual optimum }\end{array}$} & \multicolumn{2}{|c|}{\begin{tabular}{|c|}
$\begin{array}{c}\text { Percentual } \\
\text { distance to ideal } \\
\text { solution }\end{array}$ \\
\end{tabular}} & \multirow[b]{2}{*}{$\mid \begin{array}{c}\text { Execution } \\
\text { time of } \\
\text { iterations } \\
\text { (sec.) }\end{array}$} & \multirow[b]{2}{*}{ Iterations } \\
\hline & & $\begin{array}{c}\mathrm{Z}_{1}-\text { Invest, } \\
\text { Oper. and } \\
\text { Maint. Costs } \\
\text { (thousands } € \text { ) }\end{array}$ & $\begin{array}{c}\mathrm{Z}_{2}- \\
\text { Transp. } \\
\text { Costs } \\
\text { (€/day) }\end{array}$ & $\begin{array}{l}\mathrm{Z}_{3} \text { - Social } \\
\text { rejection } \\
\text { (number of } \\
\text { equivalent } \\
\text { persons) }\end{array}$ & & Mini & Base & Large & $\Delta O p t 1$ & $\Delta O p t 2$ & $\Delta$ Opt3 & $\Delta \mathrm{L} 1$ & $\Delta \mathrm{L} \infty$ & & \\
\hline$\# 1$ & Opt $1(1-2 \varepsilon ; \varepsilon ; \varepsilon)$ & 46032 & 9324 & 285716 & 13 & 1 & 5 & 7 & $0,0 \%$ & $22,6 \%$ & $8,3 \%$ & $30,9 \%$ & $22,6 \%$ & 83,9 & 1122790 \\
\hline \#2 & Opt $2(\varepsilon ; 1-2 \varepsilon ; \varepsilon)$ & 55832 & 7604 & 542178 & 26 & 16 & 6 & 4 & $21,3 \%$ & $0,0 \%$ & $105,4 \%$ & $126,7 \%$ & $105,4 \%$ & 1,0 & 2508 \\
\hline \#3 & Opt $3(\varepsilon ; \varepsilon ; 1-2 \varepsilon)$ & 46956 & 10980 & 263909 & 15 & 3 & 6 & 6 & $2,0 \%$ & $44,4 \%$ & $0,0 \%$ & $46,4 \%$ & $44,4 \%$ & 2,1 & 8671 \\
\hline \#4 & Goal L $\infty$ (Norm) & 46956 & 8860 & 307494 & 15 & 3 & 6 & 6 & $2,0 \%$ & $16,5 \%$ & $16,5 \%$ & $35,0 \%$ & $16,5 \%$ & 15,3 & 55585 \\
\hline \#5 & $\begin{array}{l}\text { Goal L1 (Norm) } \\
(0,33 ; 0,33 ; 0,33)\end{array}$ & 46032 & 9324 & 285716 & 13 & 1 & 5 & 7 & $0,0 \%$ & $22,6 \%$ & $8,3 \%$ & $30,9 \%$ & $22,6 \%$ & 4,3 & 17268 \\
\hline \#6 & $\begin{array}{l}\text { Weighted } \\
(0,30 ; 0,40 ; 0,30)\end{array}$ & 46032 & 9324 & 285716 & 13 & 1 & 5 & 7 & $0,0 \%$ & $22,6 \%$ & $8,3 \%$ & $30,9 \%$ & $22,6 \%$ & 3,2 & 7312 \\
\hline$\# 7$ & $\begin{array}{l}\text { Weighted } \\
(0,25 ; 0,50 ; 0,25)\end{array}$ & 46956 & 8732 & 311140 & 15 & 3 & 6 & 6 & $2,0 \%$ & $14,8 \%$ & $17,9 \%$ & $34,7 \%$ & $17,9 \%$ & 2,3 & 6470 \\
\hline \#8 & $\begin{array}{l}\text { Weighted } \\
(0,20 ; 0,60 ; 0,20)\end{array}$ & 46956 & 8570 & 322866 & 15 & 3 & 6 & 6 & $2,0 \%$ & $12,7 \%$ & $22,3 \%$ & $37,0 \%$ & $22,3 \%$ & 2,6 & 6304 \\
\hline$\# 9$ & $\begin{array}{l}\text { Weighted } \\
(0,15 ; 0,70 ; 0,15)\end{array}$ & 49336 & 8062 & 369669 & 19 & 8 & 6 & 5 & $7,2 \%$ & $6,0 \%$ & $40,1 \%$ & $53,3 \%$ & $40,1 \%$ & 2,1 & 5347 \\
\hline$\# 10$ & $\begin{array}{l}\text { Weighted } \\
(0,10 ; 0,80 ; 0,10)\end{array}$ & 50176 & 7788 & 434713 & 20 & 8 & 8 & 4 & $9,0 \%$ & $2,4 \%$ & $64,7 \%$ & $76,1 \%$ & $64,7 \%$ & 2,8 & 4923 \\
\hline \multirow[t]{3}{*}{$\# 11$} & $\begin{array}{l}\text { Weighted } \\
(0,05 ; 0,90 ; 0,05)\end{array}$ & 51632 & 7641 & 482066 & 22 & 11 & 7 & 4 & $12,2 \%$ & $0,5 \%$ & $82,7 \%$ & $95,3 \%$ & $82,7 \%$ & 2,8 & 3865 \\
\hline & Ideal & 46032 & 7604 & 263909 & & & & & $0,0 \%$ & $0,0 \%$ & $0,0 \%$ & $30,9 \%$ & $16,5 \%$ & & \\
\hline & Nadir & 55832 & 10980 & 542178 & & & & & $21,3 \%$ & $44,4 \%$ & $105,4 \%$ & $126,7 \%$ & $105,4 \%$ & & \\
\hline
\end{tabular}

Table 2: Summary of eleven representative non-dominated solutions

generated.

The eleven solutions obtained and the ideal and nadir solutions are represented in a representation that allows 3D viewing some of the points belonging to the Pareto front (Figure 2(a)). To have a clear perception of distribution of points, we also present three projections in $2 \mathrm{D}$ in Figures 2(b), 2(c) and 2(d).

(a)

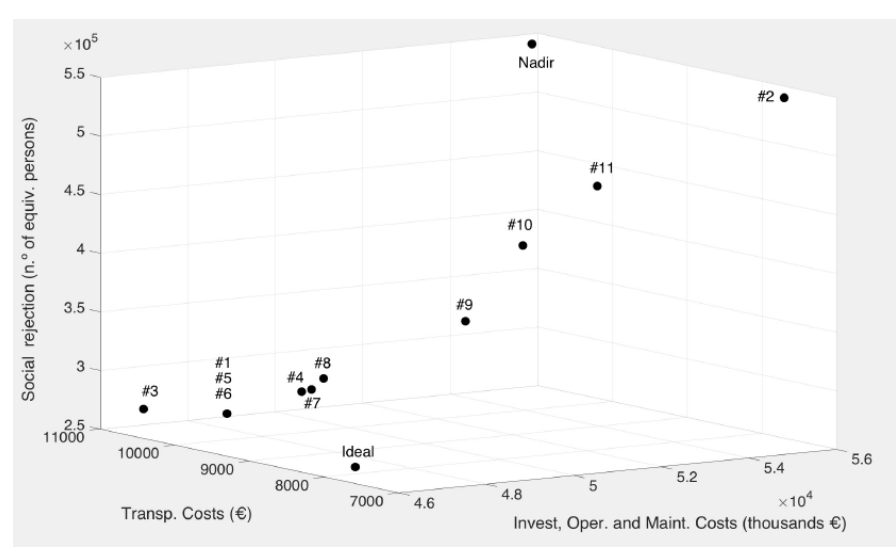

(b)

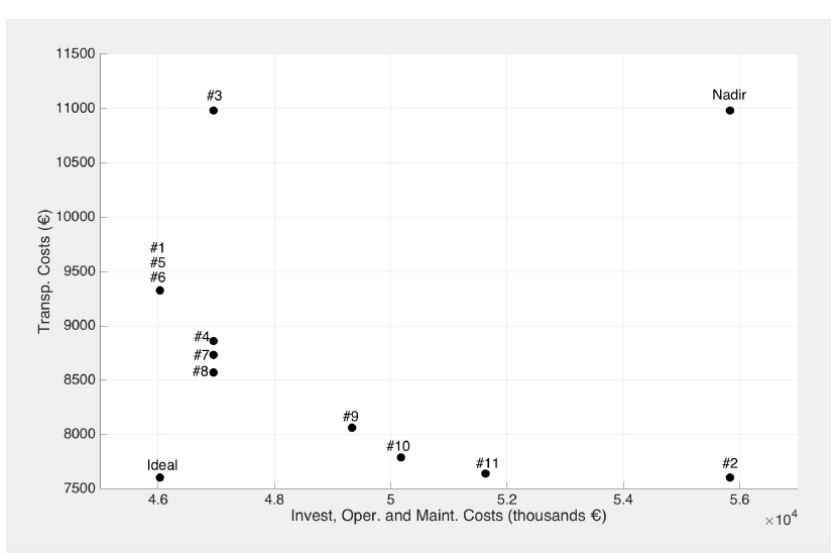


(c)

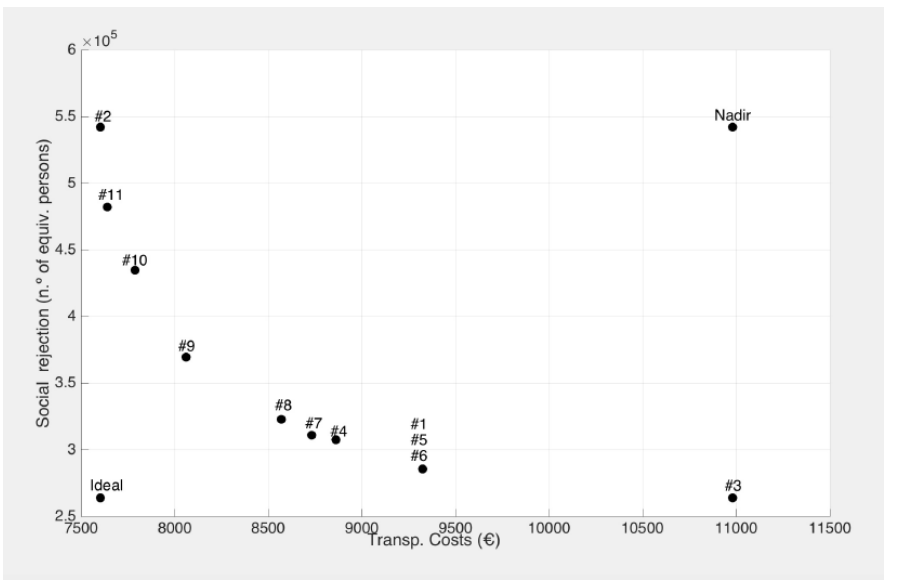

(d)

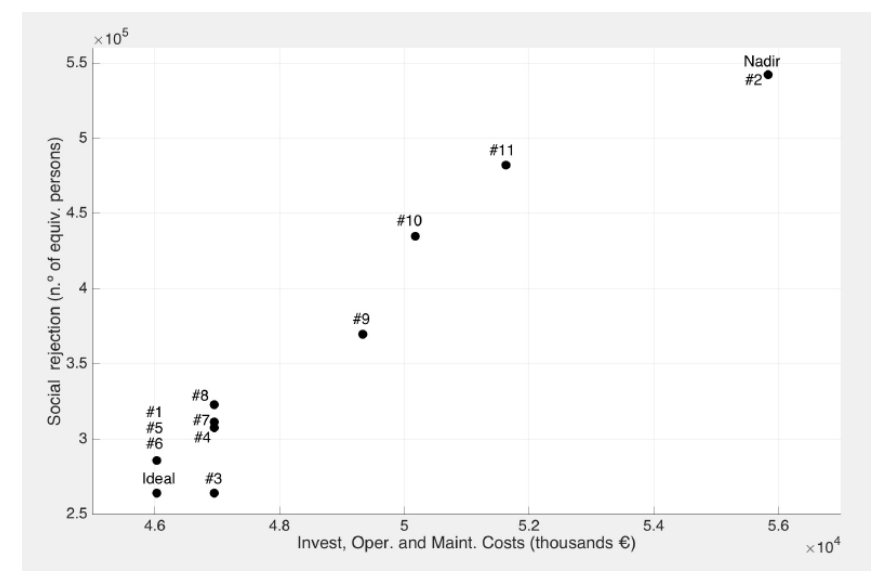

Figure 2: Pareto front considering the eleven solutions obtained as well as the ideal and nadir solutions: (a) $3 \mathrm{D}$ representation with $Z_{1}, Z_{2}$ and $Z_{3}$; (b) $2 \mathrm{D}$ projection of $Z_{1}$ and $Z_{2}$; (c) $2 \mathrm{D}$ projection of $Z_{2}$ and $Z_{3} ;$ (d) 2D projection of $Z_{1}$ and $Z_{3}$.

The comparison among a particular subset of solutions may be accomplished through a graphical representation in the objective space, the BAGAL (Alçada-Almeida et al., 2009; Coutinho-Rodrigues, et al., 2012). This diagram displays the quality of each solution as a triangle in relation to the ideal and nadir solutions (Figure 3). The inner triangle corresponds to the ideal solution; solutions closer to it are the best ones. The outer triangle corresponds to the nadir solution. The solutions Opt1, Opt2 and Opt3, as well as solutions "Goal L1 (Norm) $(0.33 ; 0.33 ; 0.33)$ " and "Goal Lo (Norm)" are also depicted as triangles in Figure 3. BAGAL has an intuitive interpretation: the closer a line is to the centre, the better is the associated solution. In Figure 3 we can observe that the two goal solutions "L1 (Norm)" and "Lo (Norm)" offer a significant improvement over Opt3 on transportation costs, without worsening much the two remaining objectives. Comparing the two goal solutions "L1 (Norm)" and "L $\infty$ (Norm)" with Opt2, we observe a huge improvement in the first and third objectives, while the second objective lies about midway between the nadir and the ideal value.

Solution "Goal L1 (Norm)" would open 13 biogas plants ( 1 of type Mini, 5 of type Medium and 7 of type Large), whereas solution "Goal L $\infty$ (Norm)" would open 15 plants ( 3 of type Mini, 6 of type Medium and 6 of type Large). Thirteen of the sites coincide in these solutions and the type of plant and the amount of manure treated is similar for most of them, but the dairy farms assigned to each site are different (Table 3). Only one biogas plant does not use the total capacity in both solutions: Site 15 in "Goal L1 (Norm)" uses $86 \%$ of the maximum capacity for type Large and Site 22 in "Goal Lo (Norm)" uses $92 \%$ of the maximum capacity for type Medium. It is possible to analyse the minimum, maximum and average distance between biogas plants and dairy farms: the minimum distance is $0.3 \mathrm{~km}$ in both solutions and the maximum distance is a little more than $29 \mathrm{~km}$. 


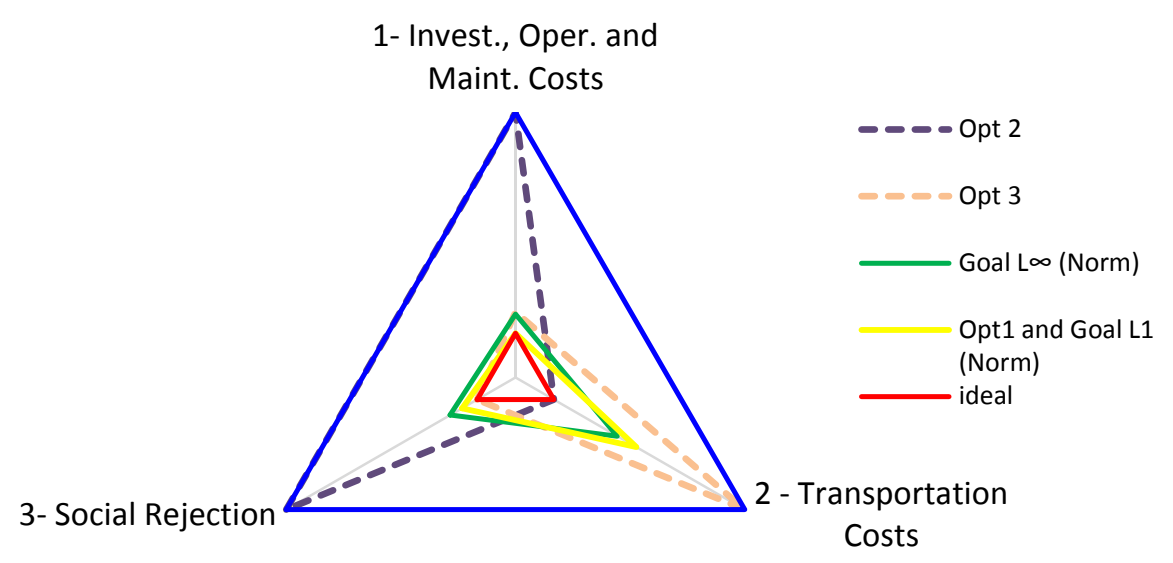

Figure 3: BAGAL - Comparisons of solutions \#1, \#2, \#3, \#4 and \#5.

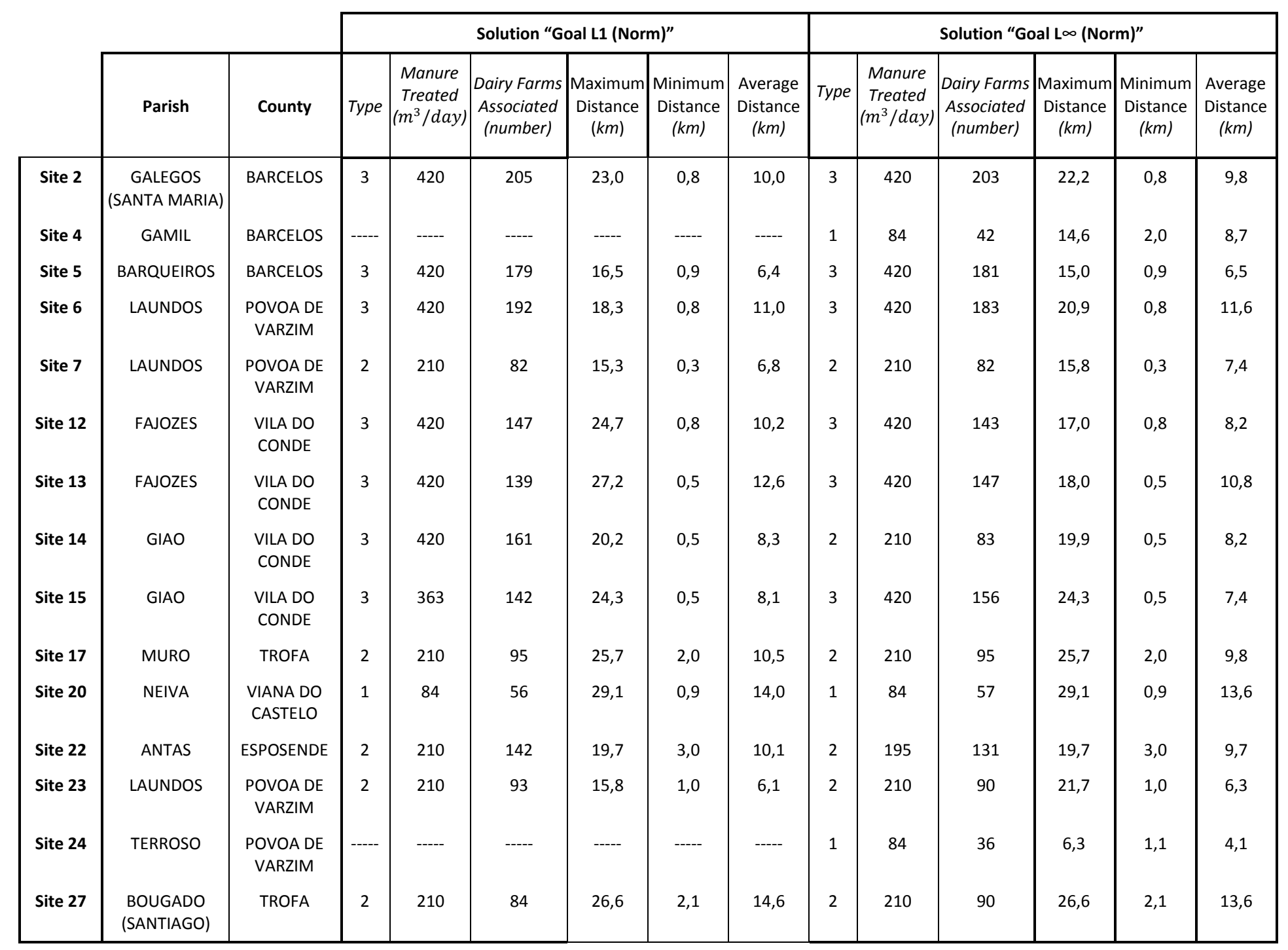

Table 3: Location, Type, amount of manure of the biogas plant on two representative efficient solutions of the Pareto frontier: "Goal L1 (Norm)" and "Goal L $\infty$ (Norm)". 
The solutions obtained were exported to a GIS in order to produce color-coded maps to facilitate the comparison in the "decision" (i.e., "geographic") space (Cohon, 1978). Figure 4 represents the dairy farms assigned to each site, for the "Goal L1 (Norm)" and "Goal L $\infty$ (Norm)" solutions, where each biogas plant is mapped with the respective dairy farm's colours.

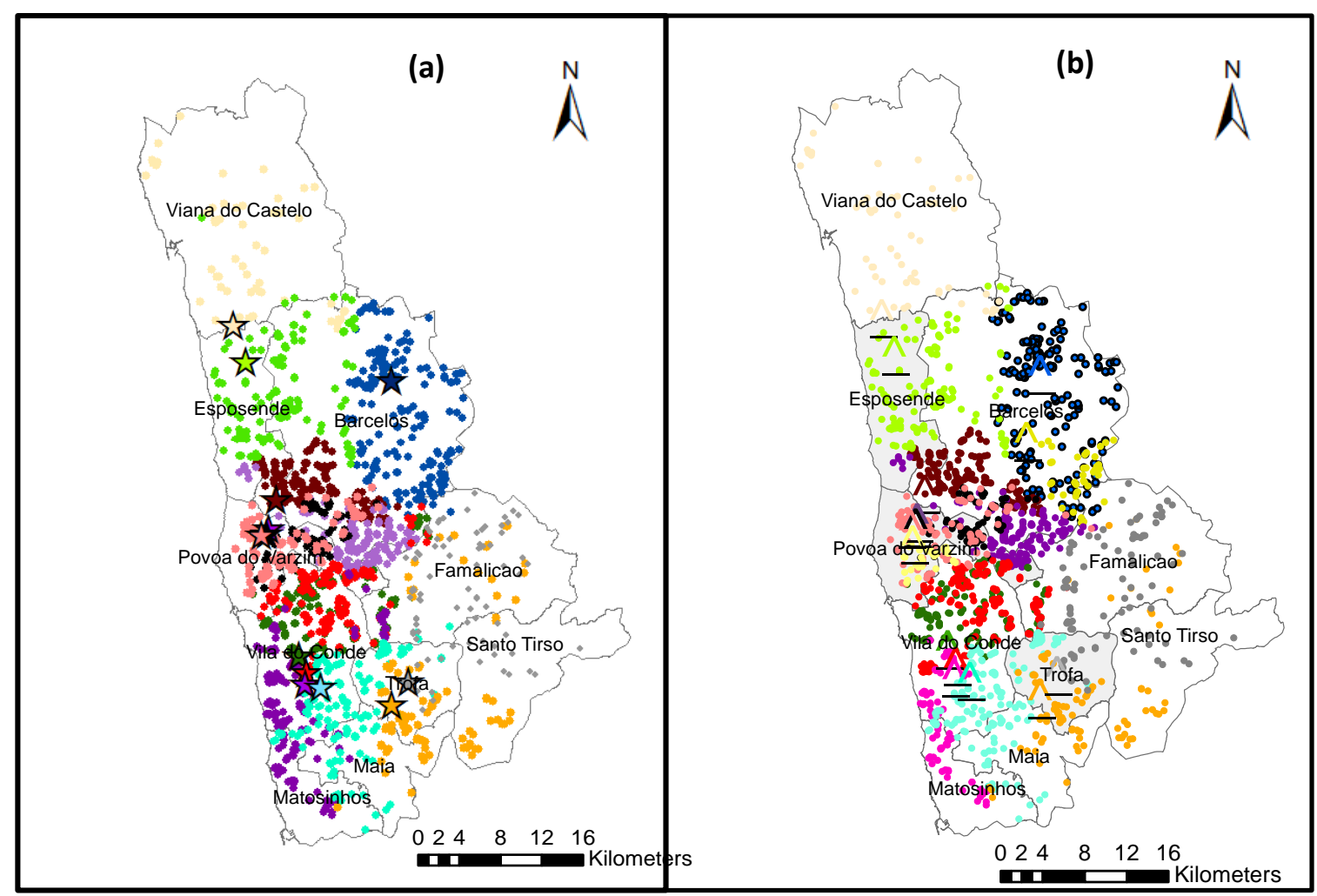

Figure 4: Dairy farms assigned to each biogas plant obtained for the (a) Goal L1 solution and (b) Goal Lo solution.

We developed a sensitivity analysis regarding the maximum distance value, considering the maximum distance of $40 \mathrm{~km}$ (the maximum value for Unal et al. (2011) and Dagnall et al. (2000)) and we verified that we obtained the same number of open biogas plants and the same type of plant for each solution. Thus, the approximately 7,000 dairy farm/biogas plant combinations added to the problem did not lead to significant changes in the solution, only slight changes in the dairy farm to plant allocations. Only two different solutions, Opt3 and Goal $L \infty$, were obtained, and only the objective function (2) changed, saving respectively $€$ 2218 and $€ 211$ when considering a distance of slightly more than $30 \mathrm{~km}$ (more specifically $32 \mathrm{~km}$ ). The use of longer distances in the routes could benefit objectives $Z_{1}$ and/or $Z_{2}$. However, it is not possible to reduce the number of open biogas plants since the fraction of its capacity used by each of them is already close to $100 \%$. We have also observed that even if no maximum distance is considered (i.e. any route is can be used), the plants that were opened were the same as the ones obtained for a limit of $40 \mathrm{~km}$. Finally, we observed that the value of the maximum distance must be greater than $29.5 \mathrm{~km}$, otherwise the problem had no solution. 


\section{Conclusions}

Complex decision problems are frequently encountered in the location of undesirable facilities, typically involving the consideration of a wide range of incommensurable and conflicting objectives. To answer to key questions as: "How many biogas plants should be located?", "How large should each biogas plant be?" and "How much manure should be assigned to each biogas plant?" we proposed a MMILP model that seeks to optimize simultaneously the economic and social performance.

The capabilities of our approach were tested through its application to a case study based on the Entre-Douro-e-Minho region. Numerical results show how it was possible to find efficient compromises between social performance, investment, operation and maintenance costs, and transportation costs. In this analysis, eleven efficient solutions were generated, using different methods, to offer the decision-maker a general understanding of the trade-offs among the objectives. The final choice should be made by a panel of experts according to their experience, and should ideally represent the views of the society or a group of stakeholders. This can be supported by informative graphical representations, namely the BAGAL and the GIS maps corresponding to different solutions.

This model has been developed mainly with the purpose of studying the number and type of plants to be sited, as well as to have an idea of the trade-offs involved among the different objectives. In future research a more accurate model can be developed, acknowledging that:

- It was not the purpose of this paper to optimize the routes of manure collection (locating-routing problem). Indeed, this would require making assumptions on who would organize the manure collection and how its costs would be distributed.

- The data concerning manure production do not account for possible expansion or reduction plans by the farmers.

A much more comprehensive model would be quite expensive in terms of data collection and larger in terms of variables and constraints. Despite its limitations, the model presented is general enough to be purposefully applied to other regions and other undesirable facilities, after performing a careful adaptation to the local features of the region and type of facility.

\section{Acknowledgement}

The authors acknowledge support by FCT Program PEst-OE/EEI/UI0308/2014.

\section{References}

ADENE, 2003. Estudo de viabilidade do tratamento centralizado de resíduos agro-pecuários no Concelho de Montemor-o-Novo (Feasibility study for centralised processing of farm waste in the Municipality of Montemor-o-Novo). Energy Agency (ADENE).

AEBIOM, 2009. A Biogas Road Map for Europe. European Biomass Association. Available at:

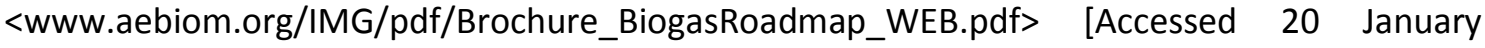
2016].

Al Seadi T, Rutz D, Prassl H, Köttner M, Finsterwalder T. Biogas Handbook. ISBN 978-87992962-0-0. University of Southern Denmark Esbjerg; 2008.

Alçada-Almeida L, Coutinho-Rodrigues J, Current J. A multiobjective modeling approach to locating incinerators. Socioecon Plann Sci 2009; 43 (2): 111-120. 
Alumur S, Kara BY. A New Model for the Hazardous Waste Location-Routing Problem. Comput Oper Res 2007; 34, 1406-1423.

Baldwin S, Lau A, Wang M, 2009. Development of a Calculator for the Techno-economic Assessment of Anaerobic Digestion Systems. Available at: <http://www.biomass.ubc.ca/IBSAL/AD\%20Calculator\%20Project\%20-\%20Final\%20Report.pdf> [Accessed 20 January 2016].

Batzias A, Sidiras K, Spyrou K. Evaluating livestock manures for biogas production: a GIS based method. Renew Energ 2005; 30: 1161-1176.

Bowman Jr VJ. On the relationship of the Tchebycheff norm and the efficient frontier of multiple-criteria objectives. In: Thiriez $\mathrm{H}$, Zionts $\mathrm{S}$, editors. Multiple criteria decision making, lecture notes in economics and mathematical systems, vol. 130. Berlin: Springer-Verlag; pp. 76-86; 1976.

Caballero R, Gonzalez M, Guerrero FM, Molina J, Paralera C. Solving a multi-objective location routing problem with a meta-heuristic based on tabu search: Application to a real case in Andalusia. Eur J Oper Res 2007; 177: 1751-1763.

Cappanera P, Gallo G, Maffioli F. Discrete Facility Location and Routing of Obnoxious Facilities. Discrete Appl Math 2004; 133: 3-28.

Caslin B, 2009. Potential of farm scale $A D$ in Ireland. Available at: $<$ http://www.seai.ie/Renewables/AD In Ireland 22nd October/Potential of Farm Scale AD in Ireland.pdf.> [Accessed 20 January 2016].

Church RL. Geographical information systems and location science. Comput Oper Res 2002; 29: 541-562.

Ciborowski P, 2001. Anaerobic Digestion of Livestock Manure for Pollution Control and Energy Production: A Feasibility Assessment. Minnesota Pollution Control Agency, United States Environmental Protection Agency. Available at: www.pca.state.mn.us/index.php/viewdocument.html?gid=9244 [Accessed 20 January 2016].

Cohon JL. Multiobjective Programming and Planning, Academic Press, New York; 1978.

Coutinho-Rodrigues J, Tralhão L, Alçada-Almeida L. A bi-objective modeling approach applied to an urban semi-desirable facility location problem. Eur J Oper Res 2012; 223(1): 203213.

Dagnall S, Hill J, Pegg D. Resource mapping and analysis of farm livestock manuresassessing the opportunities for biomass-to-energy schemes. Bioresource Technol 2000; 71:225-34.

De Meyer A, Cattrysse, D, Van Orshoven, J.A generic mathematical model to optimise strategic and tactical decisions in biomass-based supply chains (OPTIMASS). European Journal of Operational Research 2015; 245-1: 247-264.

Demuynck M, Nyns EJ, Dordrech, WP. Biogas plants in Europe: a practical hand book. Solar Energy R\&D in the European Community, Series E, Volume 6; 1984. ISBN 90-277 -1780-X.

Durão VL (Análise Comparativa de Sistemas Centralizados e Descentralizados de Valorização de Chorumes de Suiniculturas, utilizando o Sistema UMBERTO (Comparative Analysis of Centralised and Decentralised Systems Valuing Manure from pig farms using UMBERTO System). Lisboa: FCT - UNL, 2009. pp. 119. (http://hdl.handle.net/10362/1968) [Accessed 20 January 2016]

Ehrgott M. Multicriteria Optimization (Second Edition). Berlin, Springer; 2005. pp. 323. 
Erkut E, Neuman S. Analytical Models for Locating Undesirable Facilities. Eur J Oper Res 1989; 40(3):275-291.

Erkut E, Neuman S. A Multiobjective Model for Locating Undesirable Facilities. Ann Oper Res 1992; 40: 209-227.

Erkut E, Karagiannidis A, Perkoulidis G, Tjandra SA. A multicriteria facility location model for municipal solid waste management in North Greece. Eur J Oper Res 2008; 187: 1402-1421.

Farahani RZ, SteadieSeifi M, Asgari N. Multiple criteria facility location problems: A survey. Appl Math Model 2010; 34: 1689-1709.

Fonseca MC, Captivo, ME. Location of semi obnoxious facilities with capacity constraints. Studies in Locational Analysis 1996; 9: 51-52.

Giannikos I. A Multi-objective Programming Model for Locating Undesirable Facilities and Routing Hazardous Wastes. Eur J Oper Res 1998; 104(2): 333-342.

Gómez A, Zubizarreta J, Rodrigues M, Dopazo C, Fueyo N. Potential and cost of electricity generation from human and animal waste in Spain. Renew Energ 2010; 35(2): 498-505.

Holm-Nielsen JB, Al Seadi T, Oleskowicz-Popiel P. The future of anaerobic digestion and biogas utilization. Bioresour Technol 2009; 100: 5478-5484.

Jingura RM, Matengaifa R. Optimization of biogas production by anaerobic digestion for sustainable energy development in Zimbabwe. Renew Sust Energ Rev 2009; 13(5): 1116-1120.

Ma J, Scott NR, DeGloria S, Lembo AJL. Siting analysis of farm-based centralized anaerobic digester systems for distributed generation using GIS. Biomass Bioenerg 2005; 28: 591-600.

Madlener R, Antunes CH, Dias LC. Assessing the performance of biogas plants with multicriteria and data envelopment analysis. Eur J Oper Res 2009; 197: 1084-1094.

Madlener R, Schmid C. Spatial diffusion of biogas technology in Switzerland: A GIS-based multi-agent simulation approach. Int J Environ Pollut 2009; 39(1-2): 28-43.

Maeng $\mathrm{H}$, Lund $\mathrm{H}$, Hvelplund $\mathrm{F}$. Biogas plants in Denmark: technological and economic developments. Appl Energ 1999; 64: 195-206.

Melachrinoudis $\mathrm{E}$, Min $\mathrm{M}, \mathrm{Wu} \mathrm{X}$. A multiobjective model for the dynamic location of landfills. Location Science 1995; 3(3): 143-166.

Murphy JD, McKeogh E, Kiely G. Technical/economic/environmental analysis of biogas utilization. Appl Energ 2004; 77:407-427.

Naskeo Environnement, 2009. Available at: <http://www.biogas-renewableenergy.info/biogas installations expenditures.html > [Accessed 20 January 2016].

Melo M, Nickel S, Saldanha da Gama F. Facility location and supply chain management A review. European Journal of Operational Research, 2009; 196(2),401-412.

Neves LCM, Converti A, Vessoni TC. Biogas Production: New Trends for Alternative Energy Sources in Rural and Urban Zones. Chem Eng Tech 2009; 32 (8): 1147-1153.

Nielsen LH, Hjort-Gregersen K, Thygesen P, Christensen J. Socio-economic Analysis of Centralised Biogas Plants. Report no. 136, 2002. Danish Ministry of Food Agriculture and Fisheries. 
Panichelli L, Gnansounou E. GIS-based approach for defining bioenergy facilities location: A case study in Northern Spain based on marginal delivery costs and resources competition between facilities. Biomass Bioenerg 2008; 32(4): 289-300.

POBLPEMD, 2007. Plano de Ordenamento da Bacia Leiteira Primária do Entre Douro e Minho. Direção Regional de Agricultura de Entre Douro e Minho ('Entre Douro e Minho's Regional Development Plan for Dairy Farming'); Escola Superior Agrária do Instituto Politécnico de Viana do Castelo; Instituto para o Desenvolvimento Agrário da Região Norte; Universidade do Porto - $\quad$ CIBIO. 153 pp. (http://www.drapn.minagricultura.pt/drapn/fitosanidade/fil leite/relatorio final.pdf ) [Accessed 20 January 2016].

Rakas J, Teodorović D, Kim T. Multi-objective modeling for determining location of undesirable facilities. Transpot Res D Tr E 2004; 9(2): 125-138.

ReVelle CS, Eiselt HA, Daskin MS. A Bibliography for Some Fundamental Problem Categories in Discrete Location Science. Eur J Oper Res 2008; 184(3): 817-48.

Salomon KR, Lora EES. Estimate of the electric energy generating potential for different sources of biogas in Brazil. Biomass Bioenerg 2009; 33: 1101-1107.

Samanlioglu F. A multi-objective mathematical model for the industrial hazardous waste location-routing problem. Eur J Oper Res 2013; 226: 332-340.

Silva S, Alçada-Almeida L, Dias L. Biogas Plants Site Selection integrating Multicriteria Decision Aid Methods and GIS Techniques: A Case Study in a Portuguese Region. Biomass Bioenerg 2014; 71: 58-68.

Stucki M, Jungbluth N, Leuenberger M. Life Cycle Assessment of Biogas Production from Different Substrates. ESU-services Ltd, 2012. Available at: http://www.esuservices.ch/fileadmin/download/publicLCl/stucki-2011-biogas-substrates.pdf [Accessed 20 January 2016].

Sultana A, Kumar A. Optimal siting and size of bioenergy facilities using geographic information system. Appl Energ 2012, 94: 192-201.

Taleghani G, Kia ASTechnical-economical analysis of the Saveh biogas power plant. Renew Energ 2005; 30: 441-446.

Tricase C, Lombardi M. State of the art and prospects of Italian biogas production from animal sewage: Technical-economic considerations. Renewable Energy 2009; 34(3), 477-485.

Ulusoy $\mathrm{Y}$, Ulukarde AH, Ünal H, Alibas K. Analysis of biogas production in Turkey utilising three different materials and two scenarios. Afr J Agric Res 2009; 4 (10): 996-1003.

Unal HB, Yilmaz HI, Miran BOptimal Planning of Central Biogas Plants and Evaluation of Their Environmental Impacts: A Case Study from Tire, Izmir, Turkey. Ekoloji 2011; 20(79): 2128.

Voivontas D, Assimacopoulos D, Koukios EG. Assessment of biomass potential for power production: a GIS based method. Biomass 2001; 20: 101-112.

Wyman M, Kuby M. A Multiobjective Location-Allocation Model for Assessing Toxic Waste Processing Technologies. Studies in Locational Analysis 1993, 4: 193-196.

Wyman M, Kuby M. Proactive Optimization of Toxic Waste Transportation, Location and Technology. Location Science 1995; 3 (3): 167-185.

Zeleny M. Compromise Programming. In: Cochrane JL, Zeleny M, Editors, Multiple Criteria Decision Making. Columbia: University of South Carolina Press, pp. 262-301, 1973. 